\title{
Evaluation of thermal, pain, and vibration sensation thresholds in newly diagnosed Type 1 diabetic patients
}

\author{
DAN ZIEGLER, PETER MAYER, F ARNOLD GRIES \\ From the Diabetes Research Institute at the University of Düsseldorf, Düsseldorf, Federal Republic of Germany
}

SUMMARY Small and large fibre function was studied in $\mathbf{4 0}$ non-ketotic, newly diagnosed Type 1 diabetic patients and 48 age-matched controls, using 12 quantitative tests for assessment of cutaneous sensation. Patients were aged 10-39 years and had been treated with insulin for 4-31 days. Thermal discrimination (foot), warm and cold thermal perception (thenar eminence and foot), and heat and cold pain perception thresholds (thenar eminence) were significantly elevated in the patients as compared with the controls $(p<0.05$ to $p<0.001$ ). No significant differences in thermal discrimination (thenar), heat and cold pain perception (foot), and metacarpal as well as malleolar vibration perception thresholds were noted between the groups. The rates of abnormalities among the individual tests ranged from $0 \%$ to $27 \cdot 5 \%$, being lowest for vibration perception and highest for thermal perception thresholds after cold stimuli. The results in nine of 12 tests correlated significantly with age, but only two were related to $\mathrm{HbA}_{\mathrm{lc}}$. Thus, sensory neural functions transmitted by small fibres, but not those transmitted by large fibres, were impaired in newly diagnosed Type 1 diabetics after the correction of initial ketosis and hyperglycaemia. Cooling perception tests were most sensitive in detecting abnormality. An age-related involvement of different small fibre functions was present in these patients.

Quantitative assessment of various neural functions in diabetic patients provides information on the extent of deficits even at subclinical stages of diabetic polyneuropathy. ${ }^{2}$ While large myelinated $(A \alpha, A \beta)$ fibre deficits may be detected using electrophysiological techniques ${ }^{1}$ and by examination of vibration sensation, ${ }^{34}$ functional deficits of small myelinated $(\mathrm{A} \delta)$ and unmyelinated $(C)$ fibres can be assessed by testing thermal sensitivity. ${ }^{411}$ Measurement of pain sensation by thermal stimulation of nociceptive receptors has been established in only a small number of patients. ${ }^{512}$

Previous studies have demonstrated that delays in motor and sensory nerve conduction may be detected in newly diagnosed Type 1 diabetic patients. ${ }^{13-17}$ Vibration sensation deteriorated in proportion to poor glycaemic control during the first 5 years after diagnosis of non-insulin-dependent diabetes. ${ }^{18}$ Impaired thermal and vibratory perception thresholds are commonly detected in diabetic patients with neuropathic

Address for reprint requests: Dr Dan Ziegler, Diabetes-Forschungsinstitut an der Universität Düsseldorf, Auf'm Hennekamp 65, D-4000 Düsseldorf 1, Federal Republic of Germany.

Received 5 February 1988 and in revised form 25 May 1988. Accepted 20 June 1988 foot ulcerations, ${ }^{6}$ painful symptoms, ${ }^{69}$ autonomic neuropathy, ${ }^{619}$ and may also be observed in asymptomatic patients. ${ }^{10}$ However, there are no reported studies that assess small fibre function or vibratory sensation at the time of diagnosis of diabetes. Therefore, we investigated thermal, pain, and vibratory sensation thresholds in unselected, newly diagnosed Type 1 diabetic patients with stabilised near normal blood glucose levels.

Since thermal stimuli are perceived by different warm and cold receptors which in part are served by different fibres, ${ }^{2}$ both qualities were assessed separately as well as by the commonly used combined test. $^{568-10}$ Furthermore, we analysed the influence of age and prevailing glycaemic control.

\section{Patients}

Forty newly diagnosed Type 1 diabetic patients admitted to the metabolic ward of the Diabetes Research Institute participated in the study. Their clinical characteristics are shown in table 1. Criteria for the entry into the study included a history of hyperglycaemia and/or ketosis, age $<40$ years, requirement for insulin at diagnosis, duration of insulin treatment less than 5 weeks, absence of alcohol abuse and of drugs known to influence peripheral nerve function. Insulin 
Table 1 Patients clinical characteristics (mean, SD, range)

\begin{tabular}{ll}
\hline Number & 40 \\
Gender (M/F) & $27 / 13$ \\
Age (years) & $25 \cdot 6,7 \cdot 3(10-39)$ \\
Duration of insulin therapy (days) & $10 \cdot 1,5 \cdot 2(4-31)$ \\
Insulin dose (U/day) & $30,14(5-68)$ \\
Glycosylated haemoglobin (\%) - HbA 1 - Hace & $12 \cdot 0,2 \cdot 6(7 \cdot 2-19 \cdot 0)$ \\
Mean blood glucose (mmol/l) & $11 \cdot 0,2 \cdot 6(6 \cdot 5-18 \cdot 0)$ \\
Islet cell antibodies positive (n) & $7 \cdot 1,1 \cdot 6(4 \cdot 8-10 \cdot 8)$ \\
Clinical symptoms of neuropathy (n) & 0 \\
\hline
\end{tabular}

therapy was initiated in all patients using either multiple injections of regular insulin or free mixtures of regular and intermediate (NPH) insulins. After correction of ketosis and hyperglycaemia all patients were switched to two daily injections with free mixtures of regular and intermediate human or porcine insulins.

Cutaneous sensation tests were performed in the absence of ketosis for at least 4 days. None of the patients had clinical signs or symptoms of diabetic neuropathy as assessed by interview and clinical examination of tendon reflexes, motor function, pin-prick, and proprioception.

\section{Methods}

\section{Analytical methods}

Capillary blood glucose was taken on the day of the nerve function measurements using heparinised capillaries $(20 \mu \mathrm{l})$ and was determined in the hospital by the hexokinase method on an ACP 5040 autoanalyser (Eppendorf, Hamburg, FRG). Mean blood glucose was calculated as a mean of five values (fasting, postprandial, before lunch, before supper, and at bedtime). Glycosylated haemoglobin ( $\mathrm{HbA}_{\mathrm{la-c}}$ and $\left.\mathrm{HbA}_{\mathrm{lc}}\right)$ was determined with the HPLC technique using a Diamat ${ }^{\mathrm{TM}}$ analysing system (Bio-Rad Laboratories, Munich, Germany). The normal range for $\mathbf{H b A}_{1 \mathrm{a}-\mathrm{c}}$ is $5 \cdot 1-7 \cdot 3 \%$ and for $\mathrm{HbA}_{\mathrm{Ic}} 4 \cdot 4-6 \cdot 2 \%$ of total haemoglobin with coefficients of variation $<5.0 \%$.

Islet cell antibodies were assayed by indirect immunofluorescence using snap-frozen, unfixed human pancreatic sections of blood $\mathrm{O}$ donors.

Thermal and pain sensation thresholds were measured using the Marstock stimulator (Somedic, Stockholm, Sweden). The model has a stimulating surface of $25 \times 50 \mathrm{~mm}$, consisting of Peltier elements which can either be heated or cooled, depending on the direction of the electric current applied. The temperature of the plate was measured by a thermocouple and recorded by a pen recorder.

Thermal discrimination thresholds were determined as previously described. ${ }^{20}$ They are given in $\Delta^{\circ} \mathrm{C}$ as the difference between cold and warm sensation. Thermal perception thresholds were evaluated separately for warm and cold stimuli. A plate temperature of $30^{\circ} \mathrm{C}$ was used as a reference value. The subject was instructed to press the switch as soon as he perceived the plate getting warm and the temperature of the thermode would then return to the reference value. Thereafter, the investigator started a new test by pressing the switch. The same procedure was used to establish the thresholds for cold stimuli. The thermal perception threshold for both warm and cold perception is given in $\Delta^{\circ} \mathrm{C}$ as the positive difference between the absolute temperature thre- shold and the baseline temperature of $30^{\circ} \mathrm{C}$.

Heat pain and cold pain thresholds were tested as previously reported. ${ }^{20}$ The values are given as the absolute temperature of the thermode in ${ }^{\circ} \mathrm{C}$.

Thermal and pain thresholds were measured on the right thenar eminence and on the right lateral aspect of the dorsum of the foot. Normal values were obtained from $\mathbf{4 8}$ healthy volunteers aged 17-39 years (mean, SD: $28.4,5.8$ years). There were no significant correlations between tests of small fibre function and age.

Vibration perception thresholds were determined using a handheld vibrameter (Somedic, Stockholm, Sweden). The testing sites were the right medial malleolus and the distal part of the second metacarpal bone of the dorsum of the right hand in all cases. Each investigation included three readings of the lowest amplitude at which vibration was perceived (perception threshold), and of the amplitude at which the perceived vibration disappeared (disappearance threshold). The mean of 12 readings on each testing site constituted the vibration perception threshold given in $\mu \mathrm{m}$. Normal values were established in 48 healthy subjects aged 17-39 years. There was no significant correlation between age and carpal or malleolar vibration perception thresholds.

Cutaneous sensation tests were defined as abnormal if they were more than 2 standard deviations above the mean values of the age-matched control subjects.

\section{Statistical analysis}

All data were expressed by the arithmetical mean, and SD. Statistical analyses were performed using parametric methods. The $t$ test for two independent samples was applied to differences between groups. Relative frequency was calculated for qualitative variables. Single linear regression analysis was used to study relations between variables. The upper $95 \%$ confidence limits of sensory thresholds in control subjects were used to establish abnormalities in the patients.

\section{Results}

The mean values of the quantitative small and large fibre function tests in the diabetic patients and in agematched control subjects are shown in table 2 . Ther-

Table 2 Results of quantitative tests of cutaneous sensation thresholds in patients and control subjects (mean, SD)

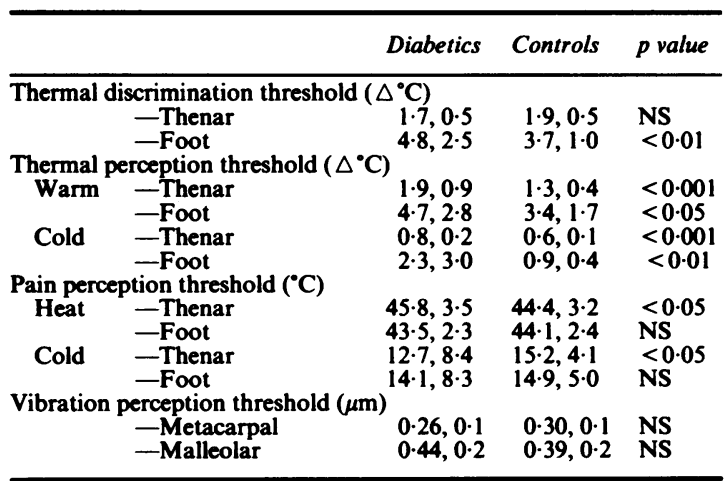

NS = not significant. 
Table 3 Number and percentages of patients with abnormalities in the individual cutaneous sensation tests

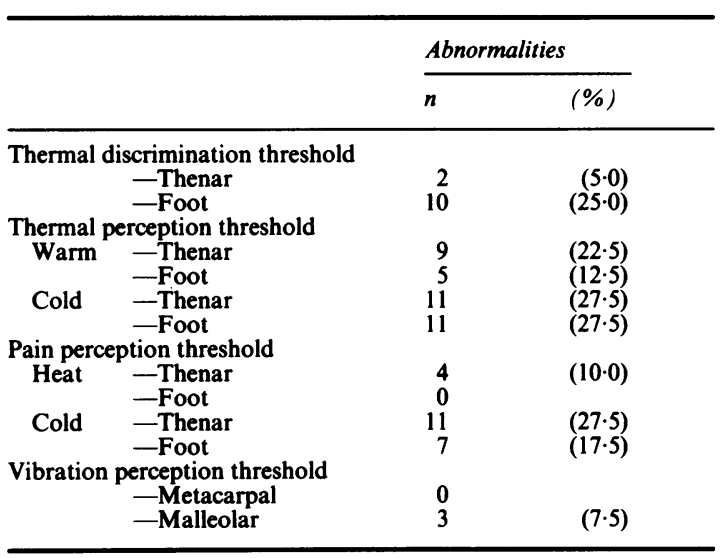

mal discrimination in the foot, warm and cold perception in the thenar and foot, and heat and cold pain perception thresholds in the thenar eminence were significantly elevated in the patients as compared with controls $(\mathrm{p}<0.05$ to $\mathrm{p}<0.001)$. There were no significant differences between groups for thermal discrimination in the thenar, heat and cold pain perception in the foot, and metacarpal and malleolar vibration perception thresholds.

Table 3 shows the extent of abnormalities detected in the individual cutaneous sensation tests. An abnormal thermal discrimination threshold was markedly more frequent on the foot than on the thenar eminence. Thermal and pain perception thresholds to cold stimuli were more frequently abnormal than those to warm stimuli. Vibration perception thresholds were less frequently abnormal than any of the five small fibre function tests when abnormal values of the feet and hands were added together.

The relationships of the individual small and large fibre function tests to age and glycaemic control are shown in table 4. Among the six functions tested on the foot, all were significantly related to age $(p<0.05$ to $p$ $<0.001$ ), whereas on the thenar only three of six functions were found to correlate significantly with age $(\mathrm{p}<0.05$ to $\mathrm{p}<0.01)$.

Significant correlations with $\mathbf{H b A}_{\mathrm{lc}}$ were observed only for thermal discrimination and warm perception thresholds of the foot $(p<0.05)$. There was no relationship between any of the nerve function tests and mean blood glucose or duration of insulin treatment.

\section{Discussion}

The results of the present study show that most of the small fibre function tests of cutaneous sensation (thermal discrimination, warm and cold perception, and heat and cold pain perception thresholds) were affected at diagnosis of Type 1 diabetes mellitus, despite treatment and correction of initial ketosis and hyperglycaemia. In contrast, the mean vibration perception threshold which is transmitted by large fibres, was not elevated in the patients as compared with age related control subjects. Previous studies in newly diagnosed diabetic patients have focused on either nerve conduction or autonomic nerve function, and have shown both to be diminished during the initial metabolic derangement, ${ }^{13-1521}$ several weeks after initiation of insulin treatment, ${ }^{1617}$ and also during the first 2 years after diagnosis of diabetes. ${ }^{22}$ No study has hitherto established whether quantitative measurements of cutaneous sensation thresholds can be used to detect abnormalities at diagnosis of diabetes. Hillson et al ${ }^{18}$ reported a deterioration in vibration sensation over 5 years after diagnosis of Type 2 (non-insulin-dependent) diabetes as an effect of hyperglycaemia, but did not show whether abnormal values were already observed initially. In recent years, various methods for assessment of thermal sensitivity have been introduced. ${ }^{4-12}$ Several authors used techniques which did not allow for separate measurements of warm and cold perception. ${ }^{8-102324}$ It is known from previous studies that warming receptors are less common than the cooling type and that the former are innervated by $\mathrm{C}$-fibres whereas the latter are supplied by $A \delta$ - and $C$-fibres. ${ }^{2}$ Since there are differences in the distribution, density, and innervation of these receptors, ${ }^{2}$ warm and cold perception may be affected differently in diabetic patients. For this reason, specific measurement of warm and cold perception thresholds? was performed in this study. Cooling receptors are extremely sensitive to decreases in skin temperature

Table 4 Correlation coefficients ( $r$ ) and $p$ values of associations of the various tests with age and glycosylated haemoglobin $\left(\mathrm{HbA}_{l c}\right)$, respectively

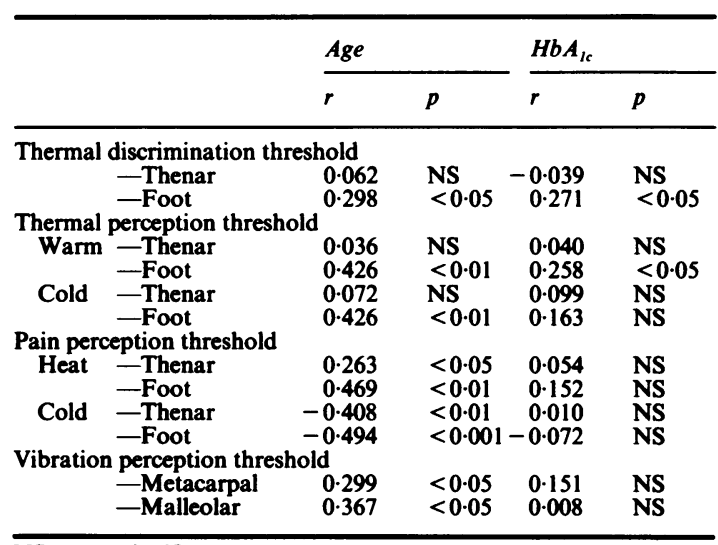

NS = not significant. 
from neutral levels between 30 and $35^{\circ} \mathrm{C}^{2}$ In diabetic polyneuropathy, the cold perception threshold in the leg has been the most sensitive thermal test. $^{1219}$ We confirm this by showing that the cold perception test on the hand and the foot was most frequently abnormal at diagnosis of Type 1 diabetes. In addition, abnormalities in thenar thermal sensation were markedly more frequent when warm and cold thresholds were tested specifically than when the combined test was used.

In this study we provide evidence that abnormalities in small fibre function precede impairment of large fibre mediated cutaneous sensation in Type 1 diabetic patients. Recently, a similar pattern of elevated thermal sensation but normal vibration sensation was demonstrated in diabetic children with a duration of diabetes ranging from 1 to 16 years. ${ }^{25}$ In diabetic patients with or without polyneuropathy, abnormalities in vibration sensation were less pronounced than those of thermal sensation..$^{6910}$

We have found that the most important determinant of elevated sensory thresholds was increasing age. Associations between sensory thresholds and $\mathbf{H b A}_{\mathbf{l c}}$, mean blood glucose or duration of insulin treatment were either weak or absent. Thus, the risk of cutaneous sensory impairment at diagnosis of Type 1 diabetes seems to be increased in elderly patients. Similarly, age related changes in sensory thresholds have been reported in diabetic patients in contrast to healthy subjects. ${ }^{10}$

As is shown in this study, pain perception thresholds after heat and cold stimuli are also impaired in newly diagnosed diabetic patients. It is known that more than $50 \%$ of $\mathrm{C}$-fibres in cutaneous nerves are nociceptive, and that more than $90 \%$ of cutaneous nerve Cfibres in hairy regions are supplied by $\mathrm{C}$-polymodal nociceptors which are excited by noxious heat $\left(>45^{\circ} \mathrm{C}\right){ }^{2}$ Recently, raised pain perception thresholds to electrical stimuli have been reported in diabetic patients with a mean duration of disease of more than 10 years. ${ }^{26}$ In contrast, reductions of pain thresholds were found in experimental animal models of diabetic neuropathy. ${ }^{27}$ Since the latter observation was made in hyperglycaemic animals, whereas our patients had near-normalised blood glucose levels, there is no basis for a comparison of these findings.

Whether the observed abnormalities reflect structural alterations in small fibre-size populations cannot be answered by this study. However, it has been suggested that in diabetic patients elevated thermal and vibration sensation thresholds are correlated with fibre loss. ${ }^{28}$ Furthermore, elevated sensory thresholds were associated with neuropathological changes in the sural nerve ${ }^{48}$ and with diminished density of cutaneous sensory receptors. ${ }^{29}$ Thus, if abnormal sensory thresholds signify neuropathologic alteration in patients with advanced stages of diabetes, it is possible that a similar alteration may already be present at diagnosis of diabetes in patients presenting with these abnormalities.

In summary, we have demonstrated a spectrum of small fibre dysfunctions in metabolically stabilised, newly diagnosed Type 1 diabetic patients. Whether these changes are predictive of progressive neuropathological alteration or of the development of clinical neuropathy remains to be established in long-term prospective studies.

The authors wish to thank M Behler and S Witt for their excellent assistance during the study, Prof Dr $\mathbf{H}$ Kolb for the measurements of islet cell antibodies, and C Heinz and P Mayer for the preparation of the manuscript.

This investigation was supported by grants from the Deutsche Forschungsgemeinschaft, Bonn, FRG, the Bundesminister für Jugend, Familie und Gesundheit, and the Minister für Wissenschaft und Forschung NRW.

\section{References}

1 Dyck PJ, Karnes J, O'Brien PC, Zimmerman IR. Detection threshold of cutaneous sensation in humans. In: Dyck PJ, Thomas PK, Lambert EH, Bunge R, eds. Peripheral Neuropathy. Philadelphia: Saunders, 1984: 1103-38.

2 Light AR, Perl ER. Peripheral sensory systems. In: Dyck PJ, Thomas PK, Lambert EH, Bunge R, eds. Peripheral Neuropathy. Philadelphia: Saunders, 1984:210-30.

3 Goldberg JM, Lindblom U. Standardised method of determining vibratory perception thresholds for diagnosis and screening in neurological investigation. J Neurol Neurosurg Psychiatry 1979;42:793-803.

4 Dyck PJ, Bushek W, Spring EM, Karnes JL, Litchy WJ, O'Brien PC, Service FJ. Vibratory and cooling detection thresholds compared with other tests in diagnosing and staging diabetic neuropathy. Diabetes Care 1987;10:432-40.

5 Fruhstorfer H, Lindblom U, Schmidt WG. Method for quantitative estimation of thermal thresholds in patients. $J$ Neurol Neurosurg Psychiatry 1976;39:1071-5.

6 Guy RJC, Clarc CA, Malcolm PN, Watkins PJ. Evaluation of thermal and vibration sensation in diabetic neuropathy. Diabetologia,1985;28:131-7.

7 Jamal GA, Weir AI, Hansen S, Ballantyne JP. An improved automated method for the measurement of thermal thresholds. 2. Patients with peripheral neuropathy. J Neurol Neurosurg Psychiatry 1985;48:361-6.

8 Bertelsmann FW, Heimans JJ, Weber EJM, van der Venn EA. Thermal discrimination thresholds in normal subjects and in patients with diabetic neuropathy. I Neurol Neurosurg Psychiatry 1985;48:686-90.

9 Heimans JJ, Bertelsmann FW, Van Rooy JCGM. Large and small nerve fiber function in painful diabetic neuropathy. J Neurol Sci 1986;74:1-9.

10 Levy DM, Abraham RR, Abraham RM. Small- and large-fibre involvement in early diabetic neuropathy: a study with the medial plantar response and sensory thresholds. Diabetes Care 
1987;10:441-7.

11 Dyck PJ, Zimmerman IR, O'Brien PC, et al. Introduction of automated systems to evaluate touch-pressure, vibration, and thermal cutaneous sensation in man. Ann Neurol 1978;4:502-10.

12 Claus D, Milz MJ, Hummer I, Neundörfer B. Methods of measurement of thermal thresholds. Acta Neurol Scand 1987;76:288-96.

13 Fraser DM, Campbell IW, Ewing DJ, Murray A, Neilson JMM, Clarke BF. Peripheral and autonomic nerve function in newly diagnosed diabetes mellitus. Diabetes 1977;26:546-50.

14 Ward JD, Fisher DJ, Barnes CG, Jessop JD. Improvement in nerve conduction following treatment in newly diagnosed diabetics. Lancet 1971;i:428-31.

15 Porte D, Graf RJ, Halter JB, Pfeifer MA, Halar E. Diabetic neuropathy and plasma glucose control. Ann Int Med 1981;70:195-200.

16 Comi G, Canal N, Lozza L, et al. Peripheral nerve abnormalities in newly-diagnosed diabetic children. Acta Diabetol Lat 1986;23:69-75.

17 Ziegler D, Cicmir I, Mayer P, Wiefels K, Gries FA. Peripheral and autonomic nerve dysfunction in newly diagnosed insulin-dependent diabetes. Transplant Proc 1986;182:1593-4.

18 Hillson RM, Hockaday TDR, Newton DJ. Hyperglycaemia is one correlate of deterioration in vibration sense during the 5 years after diagnosis of type 2 (non-insulin-dependent) diabetes. Diabetologia 1984;26:122-6.

19 Lehmann WP, Haslbeck M, Müller J, Mehnert H, Strian F. Frühdiagnose der autonomen Diabetes-Neuropathie mit Hilfe der Temperatursensibilität. Dtsch Med Wschr 1985;110:639-42.

20 Ziegler D, Mayer P, Wiefels K, Gries FA. Assessment of small and large fiber function in long-term type 1 (insulin-dependent) diabetic patients with and without painful neuropathy. Pain 1988;34:1-10.

21 Gregersen G. Variations in motor conduction velocity produced by acute changes of the metabolic state in diabetic patients. Diabetologia 1968;4:273-7.

22 Pfeifer MA, Weinberg CR, Cook DL, Reenan A, Halter JB, Ensinck JW, Porte D. Autonomic neural dysfunction in recently diagnosed diabetic subjects. Diabetes Care 1984;7:447-53.

23 Arezzo JC, Schaumburg HH, Laudadio C. Thermal sensitivity tester. Device for quantitative assessment of thermal sense in diabetic neuropathy. Diabetes 1986;35:590-2.

24 Katzenwadel A, Sachse G, Federlin K. Messung von Vibrationsempfinden und Temperaturdiskrimination bei der peripheren diabetischen Neuropathie. Akt Endokr Stoffw 1987;8:155-60.

25 Heimans JJ, Bertelsmann FW, de Beaufort CE, de Beaufort AJ, Faber YA, Bruining GJ. Quantitative sensory examination in diabetic children: assessment of thermal discrimination. Diabetic Medicine 1987;4:251-3.

26 Ionescu-Tirgoviste C, Pruna S, Bajenaru O, Cheta D, Mincu I. The perception threshold to an electric stimulus deeply applied in the lower limbs in normal and diabetic subjects. Diabetic Res Clin Pract 1987;3:249-56.

27 Wuarin-Biermann L, Zahnd GR, Kaufmann F, Burcklen L, Adler J. Hyperalgesia in spontaneous and experimental animal models of diabetic neuropathy. Diabetologia 1987;30:653-8.

28 Dyck PJ, Karnes JL, Daube J, O'Brien P, Service FJ. Clinical and neuropathological criteria for the diagnosis and staging of diabetic polyneuropathy. Brain 1985;108:861-80.

29 Dyck PJ, Winkelmann RK, Bolton CF. Quantitation of Meissner's corpuscles in hereditary neurologic disorders. Neurology 1966;16:10-17. 